\title{
Morphofunctional interpretation of the quills stridulating in tenrecs (Lipotyphla, Tenrecidae)
}

\author{
Olga V. Zherebtsova
}

\begin{abstract}
The muscles providing the stridulating of quills in tenrecs (Hemicentetes, Tenrec ecaudatus and Echinops telfairi) were studied using histological and micromorphological methods. The complicated interlacement of the hypodermic muscle (m. cutaneus trunci) attaching to the quill bases was observed in Hemicentetes and Echinops. In this case, the alternate contraction of the cross-striated fibres causes the quills ability to vibrate rapidly and to rub together producing high (Hemicentetes), or low-frequency (Echinops) sounds (Eisenberg \& Gould, 1970). The attachment of well developed mm. arrectores pilorum of the simple (Hemicentetes) and complex (Echinops) structure was also found on the bulbs of stridulating quills. Smooth skin muscles serve both for erection and elastic fixation of the quills, which is necessary prerequisite for the stridulation. In T. ecaudatus, in which the stridulating quills are completely lost in adult specimens, the individual fibres of $\mathrm{m}$. cutaneus trunci were noted in the derm of dorsum skin.
\end{abstract}

KEY WORDS: tenrecs, Hemicentetes, Tenrec ecaudatus, Echinops telfairi, stridulating quills, mm. arrectores pilorum, $\mathrm{m}$. cutaneus trunci.

Olga V. Zherebtsova [hedgol@yandex.ru], Zoological Institute, Russian Academy of Sciences, Universitetskaya nab., 1, Saint Petersburg 199034, Russia.

\section{Морфо-фуунциональная интерпретация стридулирования игл у тенреков (Lipotyphla, Tenrecidae)}

\section{О.В. Жеребцова}

РЕЗЮМЕ. Изучали мышцы, обеспечивающие стридулирование игл у тенреков (Hemicentetes, Tenrec ecaudatus и Echinops telfairi), используя микроморфологические и гистологические методы. У Hemicentetes и Echinops наблюдалось сложное переплетение подкожной мышцы (m. cutaneus trunci), прикрепляющейся на основаниях игл. В этом случае попеременное сокращение поперечно-полосатых волокон обусловливает способность игл быстро вибрировать и тереться друг о друга, производя высоко- (Hemicentetes) или низкочастотные (Echinops) звуки (Eisenberg \& Gould, 1970). На основаниях стридулирующих игл было также обнаружено прикрепление хорошо развитых $\mathrm{mm}$. arrectores pilorum простого (Hemicentetes) или сложного (Echinops) строения. Гладкие мышцы кожи служат как для выпрямления, так и для упругой фиксации игл, что является необходимой предпосылкой для стридуляции. У T. ecaudatus, у которого стридулирующие иглы полностью утрачиваются во взрослом состоянии, в дерме кожи спины отмечались отдельные волокна m. cutaneus trunci.

КЛЮЧЕВЫЕ СЛОВА: тенреки, Hemicentetes, Tenrec ecaudatus, Echinops telfairi, стридулирование игл, $\mathrm{mm}$. arrectores pilorum, $\mathrm{m}$. cutaneus trunci.

\section{Introduction}

One of the directions of the tenrec's evolution is related to the spines development variously manifesting in the Tenrecinae. For instance, in Echinops telfairi Martin, 1838 and Setifer setosus (Schreber, 1778), small spines of the same type form the continuous spinose integument on the back, whereas in Tenrec ecaudatus (Schreber, 1778), Hemicentetes semispinosus (Cuvier, 1798), and $H$. nigriceps Günter, 1875 the dorsal spines alternate with hairs and can differ significantly by their structure and functions. The phenomenon of "stridulation" was first described for Hemicentetes (Rand, 1935; Petter \& Petter-Rousseaux, 1963; Gould, 1965). This phenomenon consists in ability of some quills to vibrate rapidly and to rub together that produces the specific sound.

The stridulation is observed in all species examined; however, in each case it is variously expressed. Thus, in Hemicentetes, it is provided by a special group of quills ("stridulating organ") during whole life of the animal (Gould, 1965). It is used for the contact between female and juveniles in the postnatal period, and also for distant communication of the adult individuals in colonies of the tenrecs. In Tenrec, the stridulating quills are observed in juveniles only. At the same time in Echinops, evidently all dorsolateral spines are able to vibrate, but a special sound of low frequency is registered only in reproductive period (Eisenberg \& Gould, 1970). 
The biological significance of the stridulation is unclear up to the present, while the results of the experimental and field investigations indicate its communicative and defensive functions (Eisenberg \& Gould, 1970; Marshall \& Eisenberg, 1996). To clarify the biological role of such unique phenomenon as the stridulation the analysis of its mechanisms is necessary. There is some information about structure of the spinose integument and musculature providing mobility of the skin and its derivatives in the Tenrecinae (Dobson, 1882; Sokolov, 1973; Gambaryan \& Zherebtsova, 1988a, b; Zherebtsova, 1996). However, one can find only separate mentions on the connection of quills stridulating with the subcutaneous muscle. Thus, the features of stridulating systems in different forms of tenrecs needs more detailed study. For this purpose, the comparative morphofunctional analysis of the stridulating mechanisms was carried out in main members of the Tenrecinae. At the same time a correlation of the data obtained with data on spines mobility in other groups of mammals is important for revealing the ways of parallel or convergent evolution in Mammalia.

\section{Material and methods}

Four species of tenrecs represented by series of two-four adult specimens each, were studied: Tenrec ecaudatus (Schreber, 1778), Echinops telfairi Martin, 1838, Hemicentetes semispinosus (Cuvier, 1798), and $H$. nigriceps Günter, 1875. The specimens were preserved in $70^{\circ}$ alcohol or $5 \%$ formalin solution. The muscles providing the spine mobility were examined using histological and micromorphological methods. In the first case the skin samples from the nape and back surface of animals were sectioned and stained with gematoxylin-eosin (Romeis, 1954). The transverse, longitudinal and tangential sections of skin were studied with the help of a binocular microscope (in 6x, 12x, and $25 \mathrm{x}$ magnification) and special stain for myozin. The peculiarities of interaction of the subcutaneous muscles and spinose integument were examined using total preparations as well.

\section{Morphofunctional analysis of the quills stridulating}

\section{Hemicentetes}

Spinose integument. The whole back and lateral surfaces of the body of these relatively small (140-180 $\mathrm{mm})$ animals are covered with coarse hairs and spines alternating each other. Unlike other tenrecs, these species have a well-marked spine differentiation. Several modifications of spines can be distinguished. The dark (with darker upper half) and relatively thin spines (8$14 \mathrm{~mm}$ in length) together with dark hairs $(8-12 \mathrm{~mm})$ form a main background of the dorsum color. The light (yellowish - in H. semispinosus and white in H. nigriceps), larger and thicker spines (13-16 mm in length) make up three longitudinal stripes contrasting with the ground color. The soft and dense underfur in $\mathrm{H}$. nigriceps is more developed than in H. semispinosus, and therefore its spines are less projecting. The longest (up to $22-30 \mathrm{~mm}$ ), thin spines form a characteristic fan on the nape in both tenrecs. This region also bears shorter, white $(15-16 \mathrm{~mm})$ and dark $(13-18 \mathrm{~mm})$ spines, semispines $(10-13 \mathrm{~mm})$, and hairs $(10-11 \mathrm{~mm})$.

The peculiar feature of spines in Hemicentetes is their ability to be detached and embedded in the skin of the assailant, much like the prickles of cactus (Petter \& Petter-Rousseaux, 1963; Marshall \& Eisenberg, 1996). This is possible owing to a special inverted cuticle on the spine tips which is observed in form of serrated scales directed downwards by their points (Eisenberg \& Gould, 1970; Chernova, 2002).

According to our data, the bases of detachable spines are placed into a special sheathes, which are obviously derivatives of the hair follicules and situated partly beyond the derm into a layer of the subcutaneous fatty tissue (Zherebtsova, 2003). The spines are detached with small bases, while their sheathes are left in the skin.

At the center of lumbosacral region of the back in Hemicentetes there is also a specific group of modified mace-formed quills, which together with the appropriate subcutaneous musculature form a so called stridulating organ (Petter \& Petter-Rousseaux, 1963; Gould, 1965) (Figs. 1 and 2). These quills having larger bulbs and arranged generally in three longitudinal rows on the area about $1 \mathrm{~cm}^{2}$ are able to vibrate touching each other (Fig. 3). This results in the producing of the specific ultrasonic sounds. The number of stridulating quills in $H$. nigriceps ranges from 7 to 17 and is less on the average (11-12) than in H. semispinosus (14), the stridulating organ of which comprises from 14 to 18 quills (Eisenberg \& Gould, 1970).

In the examined specimens of $H$. nigriceps the stridulating organ includes 12-13 quills, whereas in $H$. semispinosus the number of stridulating quills is 1517. The bulbs of these modified quills are covered by special connective-tissue capsules and slightly flattened dorsoventrally. At the same time they are located outside the derm and immersed into the interlacement of the subcutaneous muscle's fibres. In this region a cluster-like fat formations underlying the capsule bases are also well conspicuous.

Mm. arrectores pilorum. The mechanism of mobility of the different spine modifications in Hemicentetes has specific features. Mm. arrectores pilorum of the detachable defensive spines were described earlier (Zherebtsova, 2003).

$\mathrm{Mm}$. arrectores pilorum of stridulating quills are well developed and attached to the caudolateral surface of their capsules extending abruptly upwards to the derm (Fig. 3A). The lack of fibres insertion on the craniolateral surface of quill bulbs, that is characteristic of other spines in Hemicentetes, can be caused by a loss (or an initial lack) of the necessity in a large turn of stridulating quills forward. The direction of these mus- 

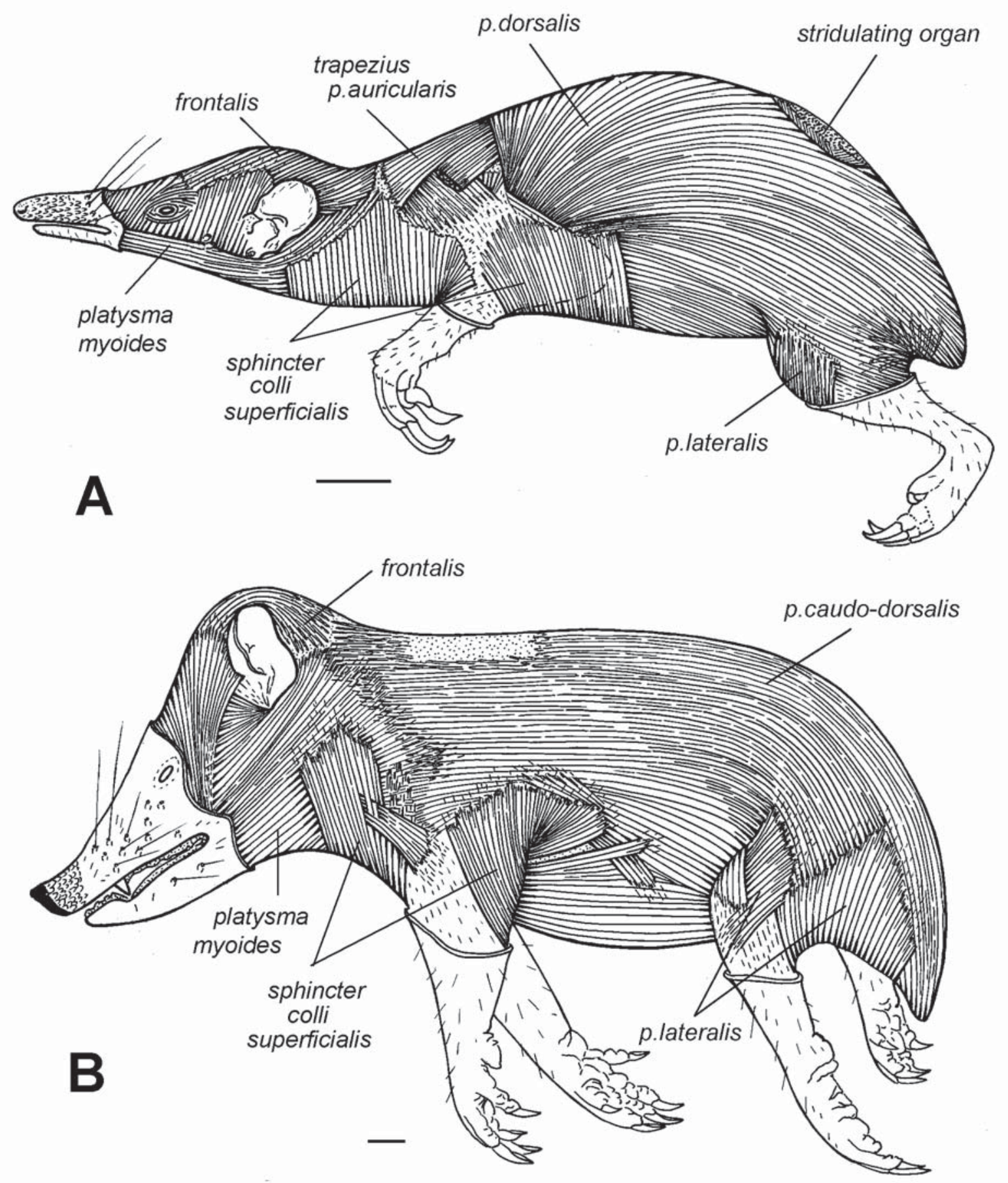

Figure 1. Subcutaneous and facial musculature of Hemicentetes semispinosus (A) and Tenrec ecaudatus (B) in lateral view. Scale bars are $1 \mathrm{~cm}$.

cles is variable, depending on a quill position in a threerow system of the stridulating organ (Fig. 3C). For instance, the fibres erecting quills of the middle row have mostly a craniocaudal direction. At the same time the function of $\mathrm{mm}$. arrectores pilorum during stridulation includes not only erection of quills, but also their elastic fixation in a definite position, so that their tips touch each other. This is attained by means of caudola- teral direction of $\mathrm{mm}$. arrectores pilorum in quills of the side rows of the stridulating organ. The contraction of these muscles results in the simultaneous deflection of the stridulating quills medially up to the contact with the quills of the central row.

M. cutaneus trunci. It consists in Hemicentetes of one layer, like in most spineless insectivorous mammals (Gambaryan \& Zherebtsova, 1988a, b), however, 

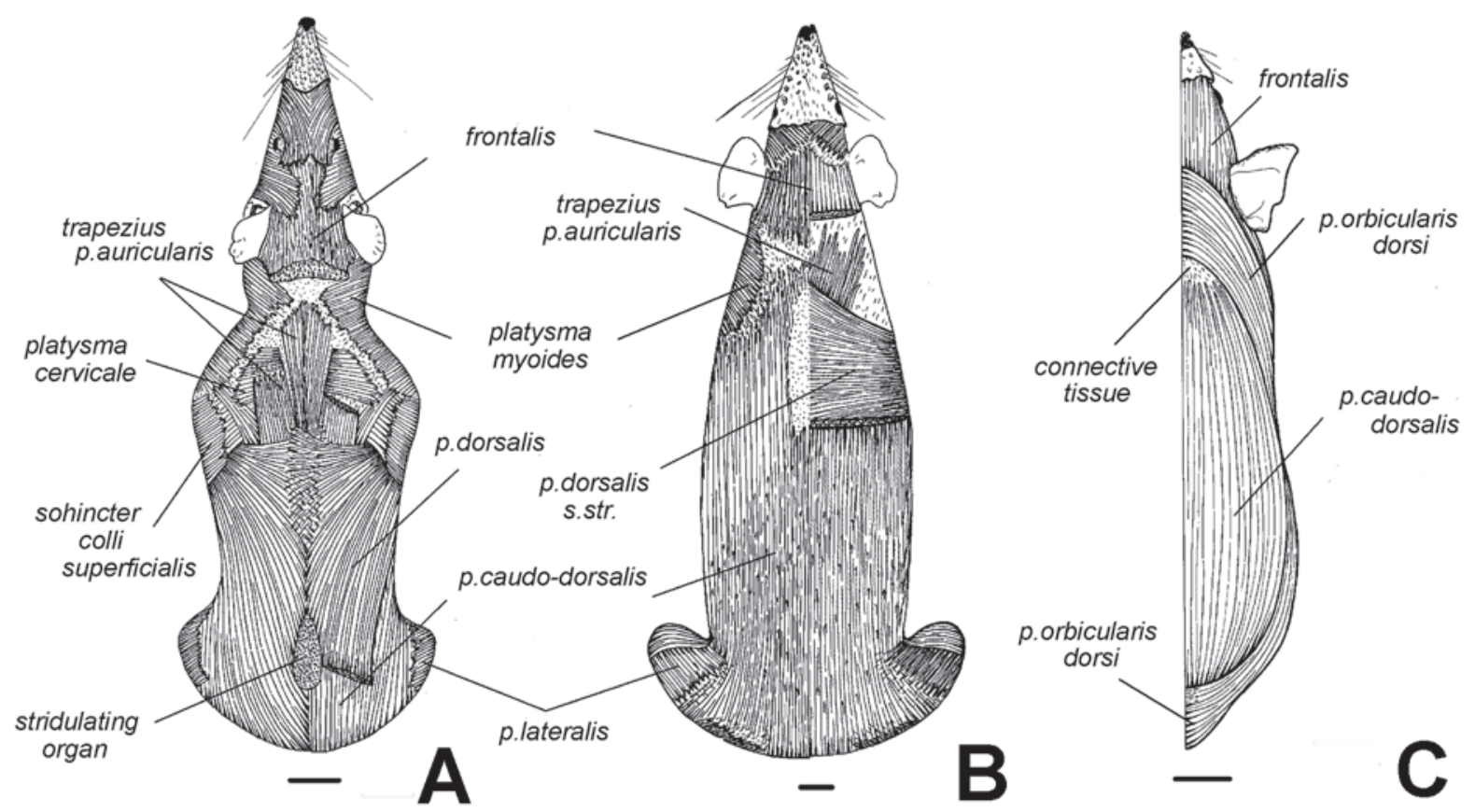

Figure 2. Subcutaneous and facial musculature of tenrecs in dorsal view.

A - Hemicentetes semispinosus; B - Tenrec ecaudatus; C - Echinops telfairi. Scale bars are $1 \mathrm{~cm}$.

a slight lamination of the dorsolateral layer does is noted (Figs. 1, 2). Part of the superficial fibres inserts by their free ends onto the skin of the dorsolateral surface of the body assisting the mobility of the spinose integument. The incipient differentiation of the subcutaneous muscle is also confirmed by a separation of a small portion of fibres ( $p$. lateralis) from the ventral layer of $\mathrm{m}$. cutaneus trunci posteriorly. These fibres turn round the femoral region from below, inserting in front and behind of it onto the skin. The function of this portion seems to be connected with the stretching and fixation of the posterior part of the spinose integument.

Part of deep fibres of the hypodermic muscle attaching on the humerus ( $p$. dorsalis) does not reach the dorsal midline, as usually, but passes parallel to it backwards and meets the fibres of $\mathrm{p}$. caudodorsalis, which run forward from the caudal vertebrae (Fig. 2). The incipient differentiation of $\mathrm{m}$. cutaneus trunci in the lumbosacral region of Hemicentetes is probably connected with the quills stridulating.

Mechanism of stridulation. Besides mm. arrectores pilorum, the capsules of the stridulating quills have an extensive attachment of $\mathrm{m}$. cutaneus trunci forming a complex interlacement there (Fig. 3A, B). The fibres, running from the humerus caudodorsally to the lumbosacral region (p. dorsalis), insert variously onto the quill capsules. A part of the superficial fibres approaching the lateral quills at an acute angle is attached to the lateral surface of their capsules. At the same time, the deeper fibres passing almost parallel to the dorsal midline insert onto the same quill capsules mediocaudally. In this case, the contraction of the superficial fibres in the quills of the left row will lead to their rotation clockwise while the contraction of the deeper fibres, to the analogous movement in the opposite direction. The quills of the right row of the stridulating organ will demonstrate the contrary situation.

The stridulating organ is also approached by the deep fibres of $m$. cutaneus trunci passing from the caudal vertebrae along the dorsal midline (p. caudodorsalis). These fibres insert onto the craniolateral surface of capsules of the lateral quills, deeper than the fibres passing from the humerus, and act as their antagonists assisting to quills rotation in the left and right rows, anticlockwise and clockwise respectively. The quills of the middle row are approached by the fibres running both from the front and behind. They are attached similarly to the quill capsules, but form a chiasm on the dorsal midline. As a result of alternate contractions of the different muscle fibres, the stridulating quills can turn very fast clockwise and anticlockwise alternatively. Apparently, this specific mechanism forms a base of the quills vibration and their rubbing together, whereas $\mathrm{mm}$. arrectores pilorum provide previously the quills erection and elastic fixation. That finally leads to the producing of specific ultrasound signals in Hemicentetes. 


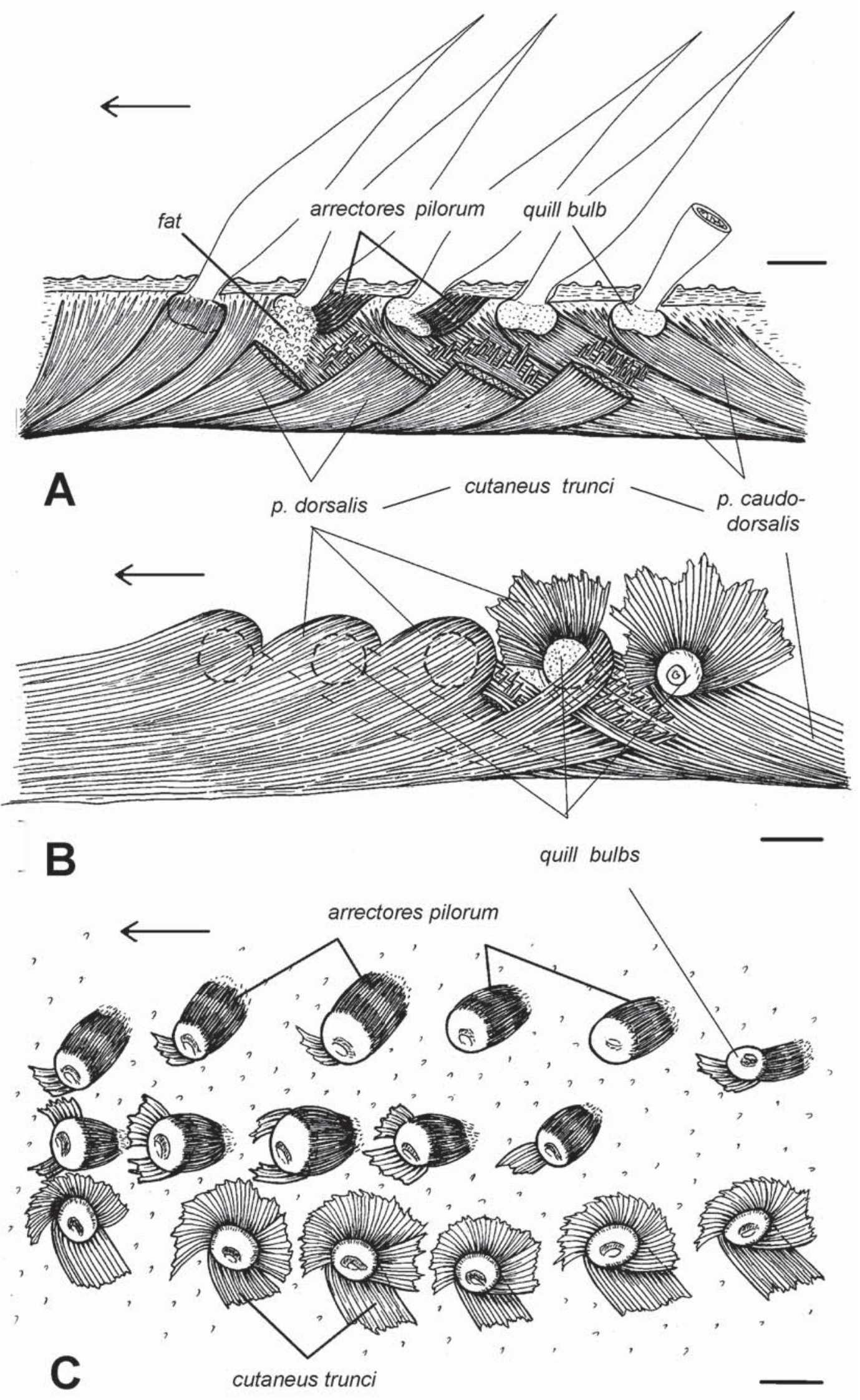




\section{Echinops telfairi}

Spinose integument. As was mentioned above, this species is characterized by a continuous spinose integument on the back that causes a great external similarity with the members of Erinaceidae. However, like in other tenrecs, the spines of this species are smaller (10 $12 \mathrm{~mm}$ in length) than in hedgehogs (Sokolov, 1973; Zherebtsova, 2000) and alternate with thin hairs. The presence of the peculiar acicular shell in E. telfairi results in essential modifications of the skin muscles.

Mm. arrectores pilorum, in comparison with other tenrecs, are most developed and have more complicated structure (Fig. 4). These muscles unite bulbs of several (2-5) spines into complexes, at that part of the fibres usually ends in the upper layer of the derm. This morphology provides simultaneous erection of all spines in a complex and their fixation in the skin. The direction and extent of the deflection of each spine are defined by a total value of all forces applied to the bulb during the contraction of smooth muscles running from it in different directions.

M. cutaneus trunci of E. telfairi is significantly strengthened and characterized by the deepest differentiation in comparison with other tenrecs (Fig. 5). It consists of two layers and has a special portion in the superficial layer (p. orbicularis dorsi), which similar in structure to the circular muscle of the hedgehogs (Gambaryan \& Zherebtsova, 1988a, b). In E. telfairi, only a small part of p. orbicularis dorsi forms a continuous ring around the back. The other fibres insert on the dorsolateral surface of caudal vertebrae or on the connective-tissue area above the base of the tail. Some of the lateral fibres (p. orbicularis lateralis) extend from this region forward attaching together with $\mathrm{m}$. frontalis to the frontal bones. The central part of the superficial dorsal layer of $\mathrm{m}$. cutaneus trunci consists of the longitudinal fibres of $\mathrm{p}$. caudodorsalis, like in T. ecaudatus. The cranial ends of these fibres get thinner and terminate into the skin of the back just behind the anterior part of the circular portion. In the caudal region, the fibres of $\mathrm{p}$. caudodorsalis pass under the $\mathrm{p}$. orbicularis dorsi, inserting by means of tendons on the dorsal surface of the posterior caudal vertebrae.

The deep layer of $\mathrm{m}$. cutaneus trunci (p. dorsalis $\mathrm{s}$. str.) in E. telfairi passes from the humerus dorsocaudally, but only the anterior part of its fibres almost reaches the dorsal midline (Fig. 5). The most part of the muscle terminates in the skin, penetrating between the longitudinal fibres of the superficial layer. The caudal part of p. dorsalis s. str. loses its attachment on the humerus, turns round the forelimb from below and inserts anterior to it into the skin.

The ventral layer of the subcutaneous muscle is specially transformed too (Fig. 5). Part of its fibres, inserting on the frontal bones, in the upper margin of orbits, passes caudoventrally between the forelimbs to the midline of the thorax ( $\mathrm{p}$. ventralis). More dorsal fibres begin between ears together with the circular muscle. These fibres turn round the lower arm in front

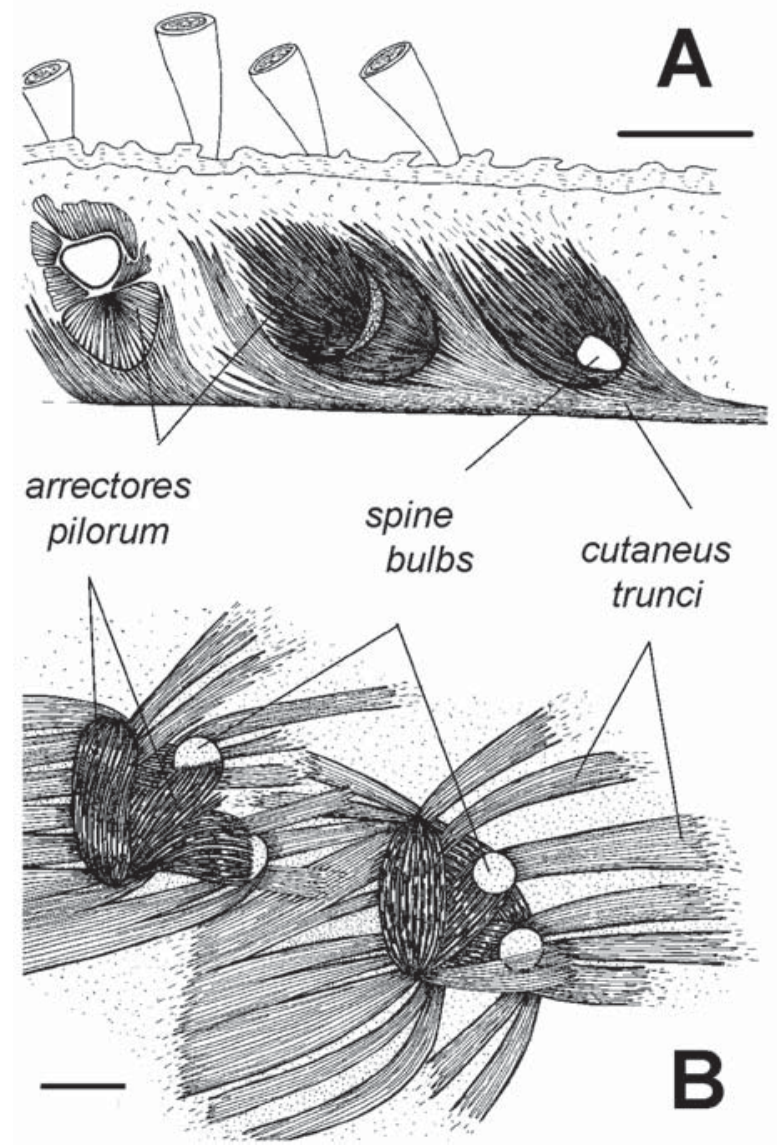

Figure 4. Scheme of mm. arrectores pilorum in Echinops telfairi in transverse (A) and tangential (B) sections made in the back region. Scale bars are $1 \mathrm{~cm}$.

and posteriorly closing up with each other and with the fibres of the dorsolateral layer of $\mathrm{m}$. cutaneus trunci and terminate partially on the belly midline ( $\mathrm{p}$. ventrolateralis). The most part of the fibres reaches the ventrolateral surface of the caudal vertebrae ( $p$. caudolateralis). A portion of fibres, turning round the hind limb from below and inserting into the derm in front and behind of it (p. lateralis), is also derivative of the ventral layer.

Mechanism of stridulation. Unlike the spinose integument of the hedgehogs (Zherebtsova, 1996), the spine bulbs of $E$. telfairi have, apart from $\mathrm{mm}$. arrectores pilorum, the attachments of $\mathrm{m}$. cutaneus trunci penetrating intensively into the skin (Fig. 4). This feature can be connected with a specific capacity of the dorsolateral spines of this species to the vibration and their light rubbing together in a reproduction period, resulted in producing low-pitched sounds (Eisenberg \& Gould, 1970). In this case the observed rhythmical movements of the spinose integument might be caused only by contraction of the cross-striated fibres of the subcutaneous muscle. The character of their attachment to the spine bulbs is rather similar to that on the stridu- 

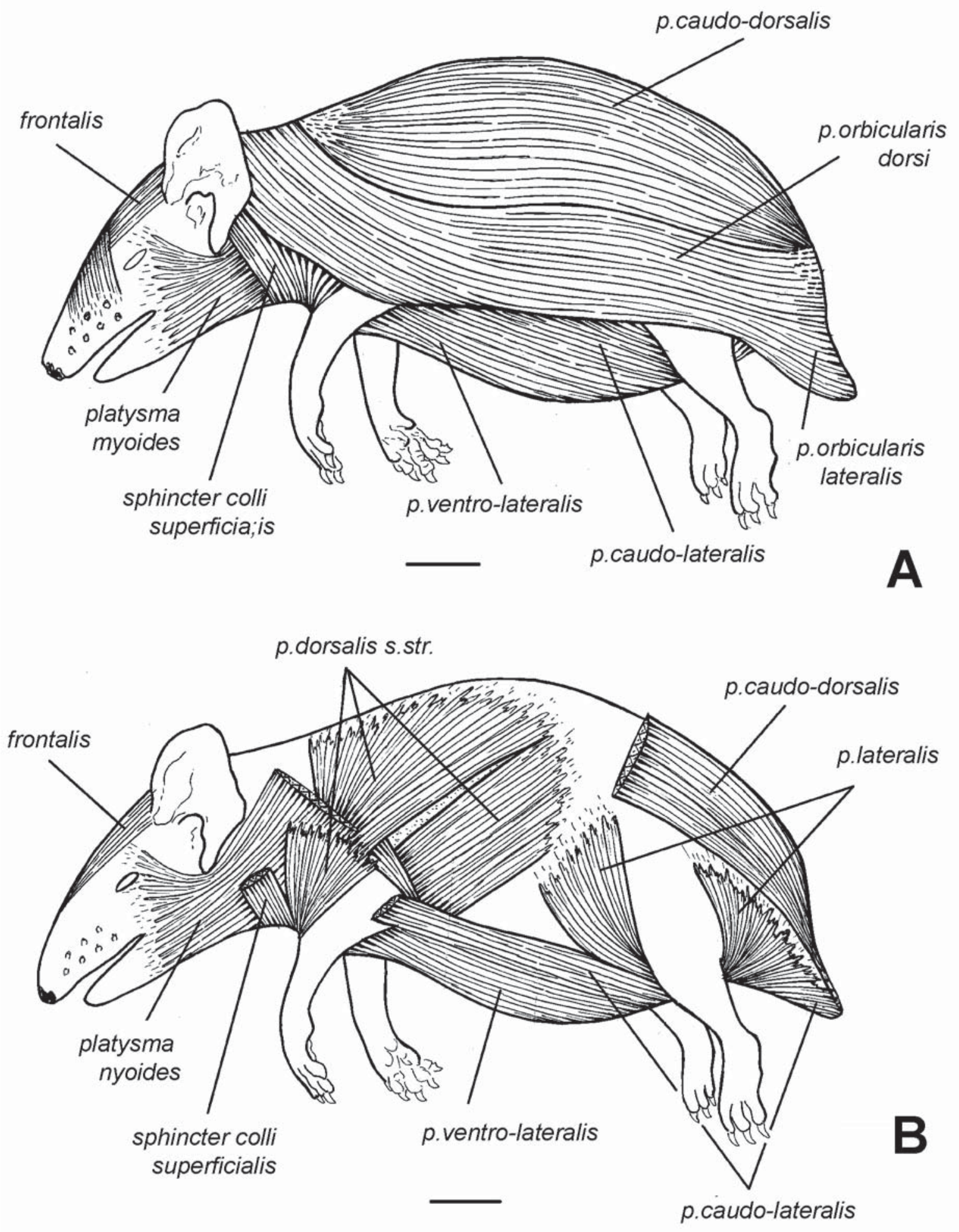

Figure 5. Subcutaneous and facial musculature of Echinops telfairi in lateral view).

A - superficial layers of muscles; B - deep layers of muscles. Scale bars are $1 \mathrm{~cm}$. 
lating quills of Hemicentetes (Fig. 3). The fibres also come to spines from the opposite sides, and, probably, their insertion on the skeleton elements is necessary. $\mathrm{Mm}$. arrectores pilorum participate evidently in this process indirectly, creating conditions for spines contacts by providing their different orientation and fixation in the skin. Thus, the stridulating mechanism in Echinops closely resembles that in Hemicentetes.

\section{Tenrec ecaudatus}

Spinose integument. The back surface of this tenrec bears a wide spectrum of hair modifications: from comparatively soft and short $(8-15 \mathrm{~mm})$ to rough and long $(27-60 \mathrm{~mm})$ bristle-like hairs. The latter are especially prominent $(75-85 \mathrm{~mm})$ along the midline of the dorsum. There are also different transitional modifications of thin, sometimes undulating, bristles and semispines of 12-33 $\mathrm{mm}$ in length. At the same time, in the inter-aural region, on the nape and dorsolateral surface of the neck, and partially on the body sides, there is a number of types of the true prickly spines: from relatively short $(10-15 \mathrm{~mm})$ and thick to the thinner and longer (18-24 mm) spines.

It is worthy mentioning that juveniles of Tenrec have five longitudinal rows of white dorsal spines. Their middle row is doubled and able to stridulation (Gould, 1965).

Mm. arrectores pilorum. The muscles erecting large bristles and spines are strongly developed, that is well noticeable on a transverse skin section in the nape region (Fig. 6A). In this case the skin gets thicker posteriorly: from $1.1-1.2 \mathrm{~mm}$ in frontal region to 1.5 $1.9 \mathrm{~mm}$ on the nape. The fibres tightly envelop small spine bulbs inserting mainly onto their craniolateral and partially lower surfaces. Then they extend fan-like backwards and upwards reaching the upper layer of the derm.

Thus, the inter-aural region and the nape of this tenrec show mainly a craniocaudal orientation of the individual $\mathrm{mm}$. arrectores pilorum, that is character of hairs as well. This structure provides turn forward of the anterior spines. The dorsolateral surface of the neck and partially of the back of T. ecaudatus indicates a variable orientation of the smooth muscles operating the individual spines (Fig. 6B, C), which is resulted in a various directions of the spines. The same areas of the skin demonstrate also a partial integration of $\mathrm{mm}$. arrectores pilorum into a small, weakly developed complex.

The smooth muscles uniting bulbs of several (2-3) semi-spines or large bristles are, as a rule, characterized by a similar craniocaudal orientation (Fig. 6C). The ends of the fibres extend backwards and insert in the upper layer of the derm. As a result of action of such muscular complex, the bristles and semi-spines will rise simultaneously providing a more rapid disheveling of hairs. The fibres of $\mathrm{mm}$. arrectores pilorum also unite bases of the spines (usually of two, more rarely of three) (Fig. 6B), but extending in this case in different direc-

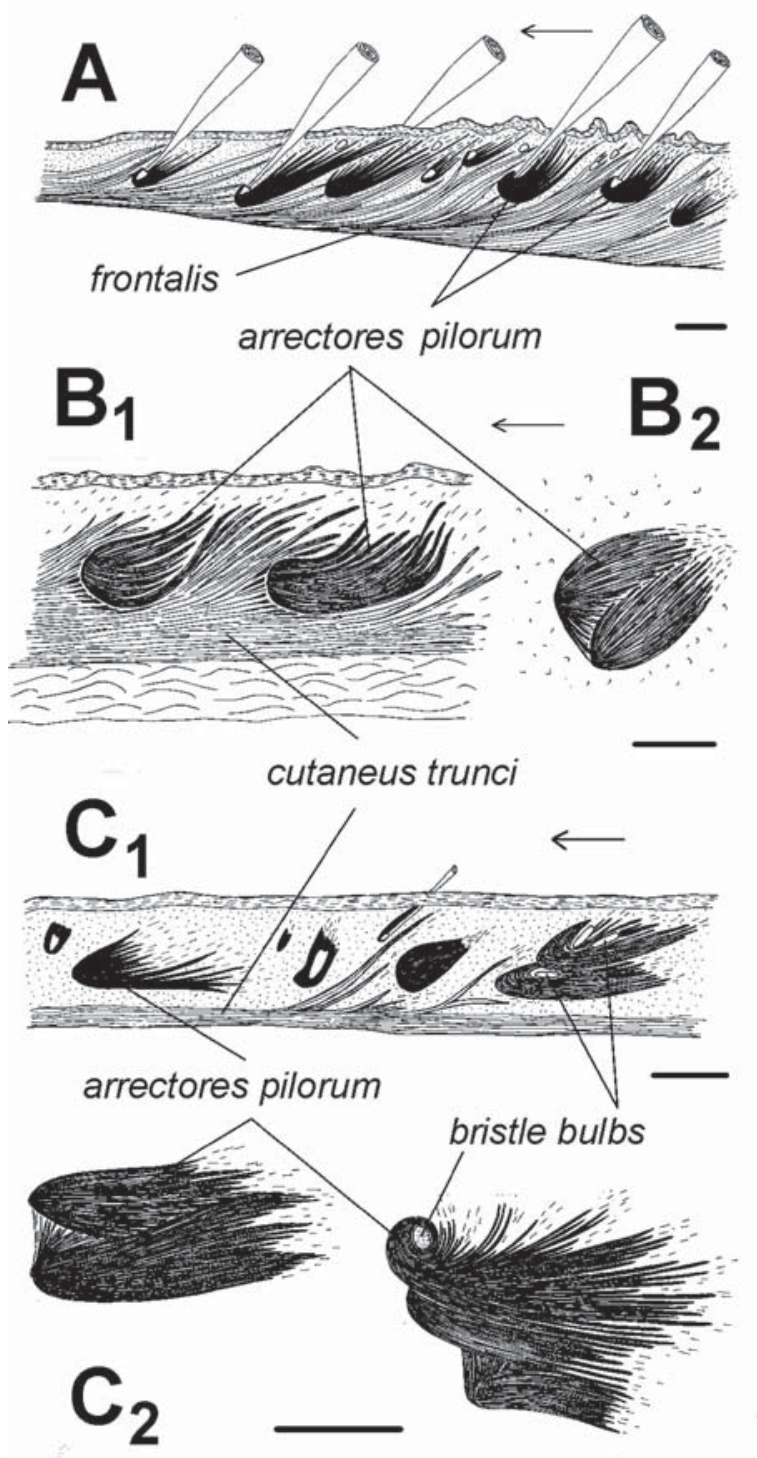

Figure 6. Scheme of mm. arrectores pilorum in Tenrec ecaudatus in transverse (1) and tangential (2) sections made in the nape (A), neck (B) and back (C) regions (arrows indicate the cranial direction). Scale bars are $1 \mathrm{~cm}$.

tions. Part of the fibres inserts near the basal membrane of the epidermis. The contraction of these muscles is resulted in a various directions of spines and their fixation in this position.

M. cutaneus trunci. Its dorsolateral part consists of two layers (Figs. 1, 2); the deeper of which ( $\mathrm{p}$. dorsalis s. str.) has a common morphology, extending fan-shaped from the humerus upwards to the dorsal midline of the body. The superficial layer of hypodermic muscle runs from the caudal vertebrae cranially, covering the whole dorsal and lateral surfaces of the body by its longitudinal fibres (p. caudodorsalis) (Figs. $1,2)$. At the front, the muscle reaches the nape and inserts partially on the connective-tissue area, where also the fibres of $\mathrm{m}$. frontalis approach. In the brachial 
region, the lateral fibres form a tight interdigitation with $\mathrm{m}$. platysma myoides running from the neck. The most superficial fibres of the subcutaneous muscle insert on the skin, penetrating into its dermal layer at thoracic, sacral and femoral regions.

The ventral layer of $\mathrm{m}$. cutaneus trunci in T. ecaudatus covers the whole ventral surface of the body. Part of the fibres begins on the humerus in the axillary region, while the rest of them inserts anteriorly, on the internal surface of $\mathrm{m}$. sph. colly superficialis. A small portion of the fibres turns round a femoral region medially ( $p$. lateralis), forming an interlacement with the fibres of the dorsolateral layer in front and at the rear of the femur and attaching to the skin.

Mechanism of stridulation. In Tenrec, as mentioned above, the stridulation is observed in juveniles only and performed by double row of middorsal white quills (Eisenberg \& Muckenhirn, 1968). Further in the ontogenesis, after molting, these quills are completely lost and in adults the stridulation is absent. According to Gould (1965), after loss of stridulating quills in subadults of Tenrec, when they are disturbed, the middorsal region of their back sometimes retains the ability to vibration. That occurs, in our opinion, owing to action of $\mathrm{m}$. cutaneus trunci $\mathrm{p}$. caudodorsalis, superficial fibres of which can penetrate in the derm, but later, in adults, their connection with the skin becomes weaker (Fig. 6). It can be supposed that in juveniles the fibres of this portion insert onto the bulbs of double middorsal row of white quills providing their vibration and rubbing together. At the same time $\mathrm{mm}$. arrectores pilorum serve for the erecting and fixation of quills as in other tenrecs.

\section{Discussion}

In tenrecs, as mentioned above, the fibres of hypodermic muscle insert to spine bulbs in contrast to such of hedgehogs. This seems to be related to communicative and defensive behavior of tenrecs that are known to produce special sounds by means of spines vibration. It is just for these rapid movements the cross-striated $\mathrm{m}$. cutaneus trunci is responsible. At the same time smooth skin muscles serve for spines erection and their fixation that is a necessary condition for the stridulating.

Our analysis indicates that in Hemicentetes the individual $\mathrm{mm}$. arrectores pilorum erects the quills and turns out side rows of them to the contact with the quills of the middle row (Fig. 3). In a similar manner, the double row of stridulating quills functions probably in juveniles of Tenrec. In Echinops, by contrast, the contraction of the complexes of $\mathrm{mm}$. arrectores pilorum results in the declination of the spines in different directions and their contact with each other (Fig. 4).The latter condition promotes spine's rubbing together owing to action of the hypodermic musculature, its attachment on the quill bulbs being rather similar in Echinops and Hemicentetes.

The fact, that juvenile Tenrec greatly resembles Hemicentetes is worthy of a special attention. It should be noted that their similarity is not limited by only their spines ability to stridulating (Gould \& Eisenberg, 1966; Nicoll, 1983). These animals are remarkably alike externally owing to a characteristic striped coloration and close body sizes. There are a several hypotheses, which attempt to explain the nature of this obvious similarity. Their consideration, on our opinion, is rather useful for the interpretation of stridulation role in the tenrec's life and connected with that some aspects of their phylogenesis.

According to one of the hypotheses such small on the size form as Hemicentetes could arise as a result of prematurely achieved puberty and following delay of development on the one of early stages of ontogenesis of the Tenrec ancestors, which is among largest representatives of insectivorous mammals (Gould \& Eisenberg, 1966; Nicoll, 1983). Thus, the case in point is pedomorphosis or more precisely progenetic origin of Hemicentetes is implied. This way of evolutionary modifications leads, as rule, to animal forms, which are small, early maturing and retaining a whole series of ancestral juvenile features (Shmalgauzen, 1983; Smirnov, 1991). Actually, many of these characters may be found in Hemicentetes: comparatively small size of the tenrecs (the length of the body is $13-18 \mathrm{~cm}$ ), early dates of puberty (the ability to reproduction is already observed in under yearlings), and a remarkable similarity with the juveniles of Tenrec (striped coloration of the back surface; existence of the stridulating) (Eisenberg \& Gould, 1970).

At the same time the progenesis phenomenon is only confirmed in some groups of animals, such as tailed amphibian, insects and some other invertebrates (Smirnov, 1991). In this case there is generally a secondary simplification of organization characterized by underdevelopment and accompanied by loss of many specialization features of definite ancestral forms (Shmalgauzen, 1983). In the real situation in progenetic animals a complex display of juvenile and definite ancestral characteristics is, as rule, observed (Smirnov, 1991).

If development laws mentioned above are applied to Tenrec and Hemicentetes another situation will be indicated. The first of them is undoubtedly a most generalized form in Tenrecinae while a second one is extremely specialized on active protection and feeding (Eisenberg \& Gould, 1970; Zherebtsova, 2000). Besides that it is impossible to recognize such features of their similarity as bright striped coloration and availability of their spines to stridulate as characteristics (indications) of underdevelopment both in Hemicentetes and in juveniles of Tenrec. In contrast, this is a manifestation of the high level of their specialization as regards to communication and protection (Gould, 1965; Gould \& Eisenberg, 1970).

On the other hand, something common with definite features of Tenrec or its proposed ancestors is rather difficult to find in organization of Hemicentetes. It concerns, for instance, a skull and teeth structure (Mivart, 1871; Marshall \& Eisenberg, 1996). Furthermore, the morphofunctional peculiarities of $\mathrm{mm}$. arrectores pilorum and especially of $\mathrm{m}$. cutaneus trunci in Tenrec 
differ significantly from those of Hemicentetes (Fig. 4). In spite of generalization of many its properties, Tenrec is nevertheless closer to Echinops and characterized here as one of intermediate form on the way of development or loss of passive-protective adaptations (Zherebtsova, 2003). Therefore the stridulating mechanism in Tenrec and Hemicentetes has been evaluated variously.

Another hypothesis tries to explain a great external similarity of juvenile Tenrec and adult Hemicentetes by mimicry. It is supposed that an imitation of young Tenrec coloration is advantageous for the adult Hemicentetes owing to better protection of the first from them by the aggressive nursing female armed by large fangs (Poduschka, 1996). However, in this case a question on utility of striped coloration in juveniles of $T$. ecaudatus themselves is not clear (Eisenberg \& Gould, 1970). Version of its adaptive masking significance (Nicoll, 1983) is not quite convincing. Tenrec inhabits not only closed but also opened landscapes, and in that case the contrast white stripes on his juveniles backs should be well noticeable during mainly night feeding of these animals (Petter \& Petter-Rousseaux, !963). At the same time the data on field and experimental investigations testify of comparatively weak protection of $T$. ecaudatus since adult and especially juvenile specimens of this species are most vulnerable among spinose forms of tenrecs for terrestrial and feathered carnivores (Rand, 1936; Eisenberg \& Gould, 1970).

The hypothesis supposing mimicry of young Tenrec in our opinion is most logical and lack internal contradictions. An imitation of the bright warning coloration of adults of Hemicentetes, which are similar on the size and specialized excellently in active defense, should be advantageous to juveniles of Tenrec (Eisenberg \& Gould, 1970). It is important in this case that these forms are characterized by a sympatric spread. The assumption of the authors that this mimicry has not only visual but also acoustic properties is original and confirmed by the experimental results. This becomes possible owing to stridulating ability of middorsal spines of young Tenrec, the frequency range of the latter being coincided with such of adult Hemicentetes. Thus, it is clear why in young specimens of T. ecaudatus, when they will become adult and can defend themselves already, their striped coloration and ability to stridulating lose the urgency and disappears ultimately in two-month age approximately (Gould \& Eisenberg, 1966).

Thus, a biological role of stridulating in juvenile period in Tenrec is to be concluded not only (and probably not so much) in regulation of contacts between nursing female and its large brood on the night feeding routes (Eisenberg \& Gould, 1970). Its passiveprotective function consisting of warning and scaring off on the distance a potential enemies can be no less important. In consequence of large litters in Tenrec, in our opinion, the effect of strengthening the whole stridulating signal is possible in this case. The functioning of stridulating organ in Hemicentetes is characterized by the same motivation (that is by distant warning and scaring off). However, in this case the regulation of social contacts of specimens in large family groups, which are colonies-like on the mode of life, may have an additional significance (Gould \& Eisenberg, 1966; Marshall \& Eisenberg, 1996).

If the ability to produce definite sounds with the aid of quills is considered in wider aspect among mammals, similar features can be noted in porcupines (Hystricidae). The spinose integument of these animals includes diverse quill modifications: apart from stout and sharp fighting spines there are also long flexible ones for the demonstrative frightening of enemies, and special hollow quills-rattles locating on the tail for scaring off enemies by noise (Gorbunov, 1985). The mobility of the first two modifications of quills in Hystrix indica as in the case with the stridulating organ of Hemicentetes is realized by the joint action of $\mathrm{mm}$. arrectores pilorum and $\mathrm{m}$. cutaneus trunci (Zherebtsova, 2000). It can be supposed that mechanism of the specialized quill "rattles" functioning is complex too.

Thus, the most complicated spine movements, including the stridulation, as in comparatively archaic tenrecs and also in evolutionary more progressive members of the Hystricidae, are carried out, as a rule, by means of co-ordinate action of smooth $(\mathrm{mm}$. arrectores pilorum) and cross-striated (m. cutaneus trunci) muscles.

ACKNOWLEDGMENTS. I am grateful to Dr. R.W. Thorington (Smithsonian Institution, USA) and Dr. U. Joger (Hessisches Landesmuseum, Germany) for their help in obtaining of fixed material on tenrecs used in this work. I specially thank Dr. I. Danilov (Zoological Institute of Russian Academy of Sciences) for the revision of the English text.

\section{References}

Chernova O.F. 2002. [New data on specialized spine cuticle of porcupines (Rodentia: Hystricomorpha) and tenrecs (Insectivora: Tenrecidae)] // Doklady Akademii Nauk. Vol.384. No.4. P.570-573 [in Russian].

Dobson G.E. 1882. A Monograph of the Insectivora, Systematic and Anatomical. Pt.1. London: John van Voorst. $172 \mathrm{p}$.

Eisenberg J.F. \& Gould E. 1970. The Tenrecs: A Study in Mammalian Behavior and Evolution. Washington: Smithsonian Institution Press. 138 p.

Eisenberg J.F. \& Muckenhirn N. 1968. The reproduction and rearing of tenrecoid insectivores in captivity // International Zoological Yearbook. No.8. P.106-110.

Gambaryan P.P. \& Zherebtsova O.V. 1988a. [Transformation of hypodermic muscles caused by the development of acicular integument in Insectivora (Erinaceidae and Tenrecidae). Communication 1] // Zoologicheskii Zhurnal. Vol.67. No.1. P.79-89 [in Russian with English summary].

Gambaryan P.P. \& Zherebtsova O.V. 1988b. [Transformation of hypodermic muscles caused by the development of acicular integument in Insectivora (Erinaceidae and Tenrecidae). Communication 2] // Zoologicheskii Zhurnal. Vol.67. No.2. P.189-199 [in Russian with English summary]. 
Gorbunov A.V. 1985. [The peculiarities of the porcupine ecology in deserts of Eastern Caspian region] // Ekologiya. No.4. P.66-70 [in Russian with English summary].

Gould E. 1965. Evidence for echolocation in Tenrecidae // Proceedings of the American Philosophical Society. Vol.109. No.6. P.352-360.

Gould E. \& Eisenberg J.F. 1966. Notes on the biology of the Tenrecidae // Journal of Mammalogy. Vol.47. No.4. P.660-686.

Marshall C.D. \& Eisenberg J.F. 1996. Hemicentetes semispinosus // Mammalian species. No.541. P.1-4.

Mivart S.G. 1871. On Hemicentetes, a new genus of Insectivora, with some additional remarks on the osteology of that order // Proceedings of the Zoological Society of London. P.58-79.

Nicoll M.E. 1983. Mechanisms and consequences of large litter production in Tenrec ecaudatus // Annales de la Musée Royale de l'Afrique Centrale, Sciences Zoologiques. T.237. P.219-226.

Petter J.J. \& Petter-Rousseaux A. 1963. Notes biologiques sur les Centetinae // La Terre et la Vie. T.17. No.1. P.66-80.

Poduschka W. 1996. Hyperthelia, litter size and duration of pregnancy in the subfamily Tenrecinae Cabrera, 1925 (Mammalia: Insectivora: Tenrecidae), with remarks on the longitudinal stripe pattern in the genus Hemicentetes // Contributions to zoology. Vol.66. No.2. P.119-128.

Rand A.L. 1935. On the habits of some Madagascar mam- mals // Journal of Mammalogy. Vol.16. No.2. P.89-104. Rand A.L. 1936. The distribution and habits of Madagascar birds // Bulletin of the American Museum of Natural History. Vol.72. P.143-499.

Romeis B. 1954. [Microscopic technique]. Moskva: Inostrannaya literatura. 718 p. [in Russian].

Shmalgauzen I.I. 1983. [The Ways and Regularities of the Evolutionary Process]. Moskva: Nauka. 360 p. [in Russian].

Sokolov V.E. 1973. [Skin Integument of Mammals]. Moskva: Nauka. 488 p. [in Russian].

Zherebtsova O.V. 1996. [Mechanisms of spine mobility in insectivorous mammals with spinose amour (Erinaceidae, Tenrecidae)] // Sokolov V.E. (ed.). [Status of Theriofauna in Russia and Neighboring Countries. Transactions of the International Conference, 1-3 February 1995, Moscow]. Moskva: Teriologicheskoe Obshchestvo. P.137142 [in Russian with English summary].

Zherebtsova O.V. 2000. Spiny cover and defense strategy of mammals // Transactions of the Zoological Institute, Russian Academy of Science. Vol.286. P.169-174.

Zherebtsova O.V. 2003. [Mechanisms of spine mobility in Tenrec ecaudatus and Hemicentetes semispinosus (Insectivora, Tenrecidae)] // Zherebtsova O.V. \& Nikulina A.N. (ed.). [Theriological Investigations. No.2]. SanktPeterburg: Teriologicheskoe Obshchestvo. P.139-147 [in Russian with English summary]. 